\title{
Procesos santiaguistas. El proceso del judío sefardí Judá Malaguí y don Alonso de Ercilla, autor de La Araucana (Madrid, 1590)
}

\section{Santiago's Order trials. The trial of the Sephardic Jew Judah Malaguí and Don Alonso de Ercilla, author of La Araucana (Madrid, 1590)}

\author{
Pedro Andrés PORRAS ARBOLEDAS \\ Catedrático acreditado de Historia del Derecho \\ Departamento de Historia del Derecho \\ Instituto de Metodología e Historia de la Ciencia Jurídica \\ Facultad de Derecho. Universidad Complutense de Madrid \\ pporras@der.ucm.es
}

Recibido: 6 de junio de 2014

Aceptado: 3 de septiembre de 2014

\section{RESUMEN}

El azar ha querido que se conserve dentro de los fondos del Consejo de Órdenes un proceso en el que tuvo una participación activa don Alonso de Ercilla, autor de La Araucana; a la altura de 1590 un mercader tetuaní de origen sefardí, Judá Malaguí, anduvo por Castilla contratando con miembros de la nobleza productos de lujo; la propiedad de una costosa sortija con una piedra jaquelada dio lugar a un proceso civil, en el que tomó parte don Alonso como testigo de ambas partes.

PALABRAS CLAVE: Don Alonso de Ercilla, La Araucana, doña María de Granada, conde de Ureña, marqués de Peñafiel, marqués de Marineo.

\begin{abstract}
Come about by chance within the documents of the Orders' Council, a trial followed to Alonso de Ercilla, author of La Araucana has been preserved. In 1590 a merchant from Tetuán of Sephardic origin, Judah Malaguí, travelled Castile dealing with luxury products for members of the nobility; the ownership of an expensive ring with a delicately carved stone resulted in a civil action, in which Alonso took part as a witness for both parties.
\end{abstract}

KEYWORDS: Don Alonso de Ercilla, La Araucana, doña Maria de Granada, count of Ureña, marquis of Peñafiel, marquis of Marineo.

\section{RÉSUMÉ}

Le hasard a voulu que dans les fonds du Conseil des Ordres il a été conservé un procès dans lequel a participé Alonso de Ercilla, auteur de La Araucana; vers 1590, avec un marchand d'origine séfarade provenant de Tetuán, Juda Malaguí. Le juif traversait Castille en contractant des produits de luxe avec 
les membres de la noblesse. La propriété d'une bague très chère avec une pierre jaqueladée a conduit à une action civile, dans laquelle Alonso a pris part comme témoin des deux parties.

MOTS CLÉ : Don Alonso de Ercilla, La Araucana, Doña María de Grenade, comte de Ureña, marquis de Peñafiel, marquis de Marineo.

Entre marzo y noviembre de 1590 tuvo lugar en Madrid un proceso de naturaleza civil por la propiedad de una sortija; el órgano ante el que se litigó fue el Consejo de las Órdenes, por ser el demandado caballero de la Orden de Santiago, algo que compartía con cierto número de los implicados y testigos en el mismo. En principio, el proceso no revistiría un interés nada especial si no fuese porque el actor demandante fue un supuesto judío de Tetuán, Judá Malaguí, cuyo apellido delata un más que probable origen sefardí, que andaba negociando en Castilla con el correspondiente pasaporte real, ya que los de su condición tenían prohibida su entrada en el país. Digo 'supuesto judío' porque al final del proceso, que quedó inconcluso, no queda claro si Malaguí era un judío tetuaní o un cristiano genovés. ${ }^{1}$

Sin embargo, lo que singulariza este pleito $-\mathrm{y}$ es el motivo de que lo traigamos aquí a colación- es la participación en el mismo de don Alonso de Ercilla, que a la sazón contaba con 52 o 53 años, según declaración propia, caballero también de Santiago, una vez asentado en la Corte desde años atrás y muchos después de su participación en la conquista de Chile y de la redacción de su epopeya, La Araucana (editada progresivamente en 1569,1578 y 1589$){ }^{2}$

No resulta extraño que don Alonso luciera en su pecho la lagartija de la Orden, tanto por propios méritos, como por el hecho de ser hijo de Fortún de Ercilla, doctor en ambos derechos, que había sido miembro del Consejo de Órdenes, antes de ser ascendido por su valía al Consejo Real. ${ }^{3}$

Por su biógrafo sabemos cómo don Alonso anduvo sus últimos años de vida ocupado en negociaciones mercantiles de productos de lujo, por lo que no resulta ex-

\footnotetext{
${ }^{1}$ Archivo Histórico Nacional, Órdenes Militares, Archivo Histórico de Toledo, expte. 14.520. Consta de 43 folios cosidos y foliados, más media hoja y un pliego, ambos sueltos.

${ }^{2}$ Para la biografía de nuestro personaje puede verse: José Toribio Medina, La Araucana: vida de Ercilla I de Alonso de Ercilla y Zúñiga; ilustrada con grabados, documentos, notas históricas y bibliográficas y una biografía del autor, Santiago de Chile, 1916 (disponible en www.cervantesvirtual.com).

${ }^{3}$ El doctor Fortún García de Ercilla, padre de don Alonso, fue nombrado miembro del Consejo de Órdenes por el Emperador en Toledo, 17/06/1525, con quitación de 100.000 mrs., permaneciendo en el mismo puesto hasta 22/04/1528, en que fue elevado al Consejo Real (Pedro Andrés Porras Arboledas, «El Origen del Real Consejo de Órdenes de José López de Agurleta», Cuadernos de Historia del Derecho, XVI, 2009, apéndice II, pp. 345-346; para la fecha de nombramiento. La referencia a su elevación al Consejo Real en AHT, expte. 78.138). Según la biografía de Medina, falleció en Becerril, a 30/09/1534, cuando Alonso contaba con apenas un año. Si nuestro autor nació en agosto de 1533, como dice su biógrafo, al tiempo del proceso que comentamos tendría no 52 o 53 años, sino 57; evidentemente, o don Alonso olvidaba su fecha de nacimiento o mintió, quitándose años, pues, de otro modo, habría nacido años después del óbito de su padre.
} 
traordinario que conociera y mantuviera relaciones con el judío tetuaní. ${ }^{4}$ Se inicia el proceso en Madrid, el primero de marzo, cuando Judas o Judá Malaguí, vecino de Tetuán, en la parte de África, de nación judío, se presentó ante el Consejo de las Órdenes y ofició demanda contra el marqués de Peñafiel: 5 Judá había comprado por 400 ducados a doña María de Granada, vecina de Madrid, ${ }^{6}$ una sortija con un diamante grande jaquelado, con forma de corazón; el mercader le había mostrado al marqués el anillo, el cual se lo apropió y empeñó en manos de don Diego Pacheco, ${ }^{7}$ caballero de la Orden, en 100 escudos; el judío, por no perder la valiosa joya, la desempeñó, pagando esa cantidad, pero Pacheco no aceptó ni la devolvió, quedándosela. El judío pidió se le reintegrase la presea, mostrándose dispuesto a abonar los 100 escudos a Pacheco. Como en todos los demás autos en que toma parte, el Malaguí plasmó al pie su firma en caracteres hebreos.

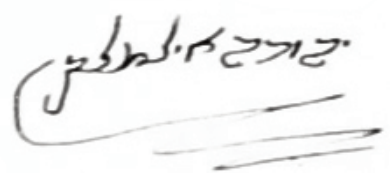

Firma de Judá Malaguí

(Yehuda il-Malagi)

La contestación a la demanda se demoró hasta el día 10, en que en un escrito firmado por el Lcdo. Arias, el procurador Juan de Alvear y el propio don Diego, negaban la mayor: la relación hecha en el escrito inicial era no verdadera, porque yo no resceví la sortija que la parte contraria pide y nunca había dicho que la devolvería. Pasados tres días, el Malaguí, tras oír la respuesta, se reafirmó en sus pretensiones, declarando los señores del Consejo tener el pleito concluso para probanzas. El 10 de abril el actor acusó primera rebeldía y el día 30 fueron recibidos a prueba con plazo de 8 días, encomendando la receptoria a Gutierre Carrillo, secretario real. En realidad, según consta asímismo en el proceso, la sentencia de recibimiento a prueba, con el mencionado plazo, fue dictada por los Lcdos. don Francisco de Albornoz y don Diego López

\footnotetext{
${ }^{4}$ Medina dedica el capítulo 13 de su biografía a los negocios del literato, relacionándose con buena parte de la nobleza estante en la Corte en la época crepuscular del reinado de Felipe II.

${ }^{5}$ Debe de tratarse de don Juan Téllez-Girón (1554-1594), segundo duque de Osuna, sexto conde de Ureña y primer marqués de Peñafiel, además de Grande de España (Ignacio Atienza Hernández, Aristocracia, poder y riqueza en la España moderna. La Casa de Osuna, siglos XV-XIX), Madrid, 1987, p. 74).

${ }^{6}$ De la vendedora sólo contamos con esta información, sin embargo cabe conjeturar con su pertenencia a la antigua casa real granadina.

${ }^{7}$ Dado que no se atribuye en el proceso ningún título nobiliario ni otra referencia, salvo su proximidad a personas de esa condición, no me ha resultado posible localizar con certeza la identidad de este sujeto. Que era personaje de linaje lo prueba el hecho de ser caballero de Santiago, tal vez segundón o bastardo de alguna rama de los marqueses de Villena.
} 
de Ayala, el día 11 de abril, siendo notificada en el día por Carrillo a don Diego en persona, en casa de don Pedro de Toledo, marqués de Villafranca, ante Juan Díaz escribano, y al Malaguí también en su presencia, siendo testigos Alonso Rodríguez del Valle y Julián Díaz, estantes en la Corte.

Nada se actuó hasta el día 7 de mayo, cuando el demandante se presentó ante el Consejo, alegando cómo él había presentado interrogatorio de testigos y pedido que el demandado jurase de calumnia sobre los puntos allí fijados, sin que hubiera querido acceder a su petición, por lo que pidió se le tuviese por confeso y le devolviese la sortija. El caso debió resultar arduo, ya que los del Consejo acordaron remitir la causa a su relator para que la viera y decidir ellos luego. La parte de Pacheco también compareció ese día y pidió una prórroga de 20 días para realizar sus informaciones de testigos. Naturalmente, el judío, que ya había realizado la información de los suyos, se opuso a la concesión de la prórroga, entendiendo que la parte del reo actuaba maliciosamente para dilatar la causa, solicitando, en su lugar, que se procediese a la publicación de testigos. A pesar de esta oposición, el Consejo concedió 10 días más a la parte de don Diego, con denegación de cualquier otro plazo. Esto sucedía el 21 de mayo, pero el día 30 el procurador Alvear expuso en su comparecencia que el marqués de Peñafiel, uno de los principales testigos, se hallaba en Valladolid, por lo que solicitaba que se librase receptoria para que prestase declaración ante la justicia de esa villa y que se prorrogase el plazo de probanzas otros 80 días. Evidentemente, deseaban ganar tiempo, sabedores de que la estancia del judío en Castilla no podía ser indefinida.

El Consejo se mostró comprensivo con el demandado, pues, además de los dos plazos de 8 y 10 días ya concedidos, le autorizaron otro de 30 más, común a las partes, bajo pena de 20 ducados si no realizase la prueba o se apartase de la causa. El 13 de junio Alvear volvía a insistir en su petición de los 80 días y de la receptoria para la justicia pucelana, sin embargo, los señores del Consejo se limitaron a confirmar el laudo de prórroga del 30 de mayo. Cinco días antes, el día 8 de junio, el Malaguí solicitó se hiciera publicación de probanzas, pues el plazo estaba consumido. Ante las tácticas dilatorias del noble, el judío acabó por estallar procedimentalmente, por decirlo así: el 15 de junio afirmó ante el tribunal que sus contrarios actuaban con evidente malicia, solicitando continuas ampliaciones del plazo probatorio, acusó rebeldía, pidió se tuviera el proceso por concluso y se hiciera la publicación de rigor, atento a lo susodicho y a que a muncho tiempo que soy solo en este negocio con muncha costa. A los del Consejo no les quedó otra opción que declarar la publicación solicitada y, en consecuencia, a ordenar a las partes que alegasen de su derecho.

Es en este momento cuando se insertan las probanzas de ambas partes:

He aquí las cuestiones introducidas en el interrogatorio del Malaguí:

$1^{\circ}$ ) si conocía a las partes y el asunto sobre que se litigaba.

$2^{\circ}$ ) fue a mostrar la sortija al marqués, que se la quedó y la empeñó en don Diego por 100 escudos. 
$3^{\circ}$ ) cuando fue a pedirla al marqués, le dijo que la tenía empeñada en 100 escudos $^{8}$ en don Diego, que fuese por ella, que él le pagaría al judío los escudos; éste le pidió la sortija a don Diego, ofreciendo a pagarle los escudos, aunque él no era el deudor; le contestó que se la daría, que bien savía que era suya, pero que estava en casa de don Alonso de Arcilla, qu'él yría por ella y se la daría, dándole los cien escudos; y esto lo saven los testigos porque se lo oyeron decir al dicho don Diego Pacheco; que digan lo que saben del asunto y si vieron la sortija en poder de don Diego.

$4^{\circ}$ ) Y si saven qu'el dicho don Diego Pacheco fue al dicho don Alonso de Ercilla y le dixo que le diese la dicha sortixa para dalla al dicho Judas Malaguí, que era suya, y le dava los cien escudos, por que estaba enpeñada y la llevó y nunca se la a dado.

$5^{\circ}$ ) la sortija con el diamante valía, a justa y comunal estimación, más de 600 escudos y el dicho Judas Malaguí la tenya en estima de más de myll escudos.

$6^{\circ}$ ) que era pública voz y fama y que la parte contraria jure de calumnia, poniendo dichas preguntas por posiciones.

He aquí las deposiciones de los testigos de su parte:

Madrid, 05/05/1590, presenta por testigo a don Alonso de Ercilla, caballero de Santiago, el cual juró a Dios y a la cruz según derecho y prometió decir verdad, preguntado por las cuestiones del interrogatorio, contestó:

A la primera pregunda dixo que conoce a las partes y tiene noticia deste pleyto e de la sortija de oro en ella conthenido.

Preguntado por las preguntas generales de la ley, dixo qu'es de hedad de cinquenta e tres años, no es pariente de ninguno de las partes ni ynteresado en esta causa, la qual bença quien tuviere justicia.

A la segunda pregunta dixo que lo en ella conthenido oyó decir a Juda Malaguí, no es acordado qué día, pero que le parece avrá más de cinco meses.

A la tercera pregunta dixo que save que la dicha sortija que es de un diamante grande jaquelado a manera de coraçón, se la enpeñó don Diego Pacheco a este testigo en docientos y veinte e cinco escudos de oro, y que el dicho don Diego Pacheco le enbió a este testigo un criado, el qual decía que traya cient escudos de oro el dicho Malaguí, que venía con el dicho criado, y que por los otros ciento y veinte y cinco tomase este testigo en prendas un cintillo de oro y rubies, que decian que valía mucho más, y este testigo no lo quiso hazer si no le davan los dichos docientos e veynte e cinco escudos en dinero, e ansí se fueron el dicho criado del dicho don Diego y el dicho Juda Malaguí, sin llevar la sortija; e de ay [a] algunos días bino el dicho criado de don Diego e truxo los dichos docientos y veinte y cinco escudos de oro y

\footnotetext{
${ }^{8}$ A lo largo del proceso cuando se habla de esa cantidad del empeño unas veces hablan de «escudos» y otras de «ducados».
} 
este testigo ordenó a Diego de Pereda, su criado, los recibiese e diese la dicha sortija, e ansi se hiço, e esto save desta pregunta.

A la quarta pregunta dixo que dize lo que dicho tiene.

A la quynta pregunta dixo que no la save.

A la sesta pregunta dixo que dize lo que dicho tiene, lo qual es la verdad y lo que save por el juramento que hiço e lo firmó de su nombre.

Ante my, Gutierre Carrillo. Don Alonso de Ercilla (firma autógrafa).

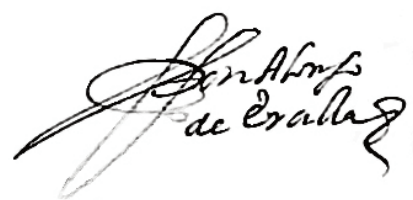

Firma de don Alonso de Ercilla

En el día, depone Diego de Pereda, criado de don Alonso de Ercilla:

Conocía a las partes y sabía del proceso.

Tenía 38 años y no era pariente.

A la segunda, que no sabía, sólo lo oyó decir al Malaguí.

A la tercera, dixo que lo que save es que Bezerra, criado de don Diego Pacheco, habló a este testigo y le dixo que benía a hablar a don Alonso Ercilla de parte de don Diego Pacheco para que le hiciese merced de tomar en prendas un cintillo de oro por ciento y veynte y cinco escudos, que le quedaría deviendo de dozientos y veinte y cinco que le devía el dicho don Diego al dicho don Alonso, porque los otros ciento los pagava Juda Malagui, y este testigo dixo que ablase con don Alonso, que él le respondería, y que el dicho día bolvió el dicho Bezerra con el dicha Juda Malagui y traya el dicho Juda Malaguí los cient escudos, y el dicho Bezerra el cintillo de oro, y este testigo los puso con el dicho don Alonso y vio que el dicho Bezerra le dio el dicho recado del dicho don Diego y el dicho don Alonso respondió que si no le davan su dinero todo no quería dar la dicha sortija, e ansí se fueron, y de ay a ciertos días topó este testigo al dicho don Diego Pacheco, junto al Hospital de Antón Martín, y le dixo el dicho don Diego a este testigo que a la noche ynbiaría por la sortija con el dicho Bezerra e llevaría los dichos docientos e veynte e cinco escudos de oro, y este testigo le dixo que ynbiase y la traería, y ansi enbió y este testigo, por mandado del dicho don Alonso, dio la dicha sortija al dicho Bezerra y recivió d'él los docientos e veynte y cinco escudos, y esto save.

A la quinta, había oído decir que la sortija valdría de 400 a 500 ducados, pero no sabía en cuánto la estimaba el judío.

Firma autógrafa.

El 8 de mayo declara Juan Tello de Moreta platero, estante en la Corte (40 años, no pariente ni enemigo). 
Sabía que la sortija se la dio Malaguí al marqués de Peñafiel, porque se lo había oído referir a éste muchas veces.

En presencia del testigo, en la calle Mayor, estando el marqués y don Diego juntos a caballo, dijo don Diego que el testigo le llevara los 100 escudos y le devolvería la sortija; cuando fue con ellos, don Diego le remitió a casa de don Alonso de Ercilla, pidiéndole que aceptase los 100 escudos y una gorra con 12 botones de oro y una medalla, en tanto le pagaba los 225 escudos en que le había empeñado la sortija; el dicho don Alonso dixo que no lo quería azer si no le pagavan toda la cantidad que le devían, porque más quería la dicha sortija que otra prenda; volvió a don Diego y le contó la respuesta de Ercilla, contestó don Diego que se levantaría y daría orden cómo el dicho don Alonso diese la dicha sortija para que la oviese Juda Malaguí, según avía dado la palabra al dicho marqués de Peñafiel.

La sortija era un diamante jaquelado muy bueno, que valía más de 400 ducados.

Firma autógrafa.

En el día depone Antonioto Lomelín genovés, estante en la Corte (27 años, no pariente ni enemigo).

Vio al marqués redactar los billetes en que pedía a don Diego que le diese la sortija a Malaguí, que éste le pagaría los 100 escudos.

Acompañó varias veces al Malaguí a casa de don Diego a pedirle la sortija, con los 100 ducados encima; otras veces el judío había mandado con el dinero a algunos criados a pedirla; don Diego nunca la dio, diciendo que la tenía empeñada en 225 escudos en don Alonso de Ercilla; que daría prendas a éste para que le diese la sortija a Malaguí, como lo tenía prometido al marqués.

Ercilla no quiso devolver la sortija si no se le pagaban los 225 escudos.

Malaguí estimaba la sortija en más de 600 escudos y él también.

Firma autógrafa

En 10 de mayo declara Pedro de Bilbao platero, vecino de Madrid (60 años, ni pariente ni enemigo).

Aclara que el Malaguí obtuvo la joya de doña María de Granada; dice que un marqués extranjero, cuyo nombre no recordaba, había sido medianero en el empeño de la sortija del marqués de Peñafiel a don Diego (el de Peñafiel debía al extranjero los 100 escudos, le transmitió la joya a don Diego, para garantizar el pago de la deuda al extranjero); cuando el Malaguí, con cédula del marqués de Peñafiel, fue por la joya, don Diego dijo que el marqués le debía, además, otros 100 escudos, de que la joya era garantía; luego se la pidieron a don Alonso de Ercilla, etc.

Valoraba la sortija en 400 ducados, poquito más o menos.

Firma autógrafa

Por su parte, el demandado presentó el siguiente interrogatorio, realizado el 29 de junio: 
$\left.1^{\circ}\right)$ Si conocían a los marqueses de Peñafiel y Marineo y sabían de la sortija.

$2^{\circ}$ ) Malaguí vendió al marqués de Peñafiel la sortija, fiada en cierto precio, otorgando a favor de aquél escritura de obligación para pagárselo, recibiéndola el marqués como cosa suya.

$3^{\circ}$ ) El marqués de Peñafiel se jugó la sortija con el marqués de Marineo y se la ganó, recibiéndola Marineo de mano de Peñafiel, disponiendo el italiano de ella a su voluntad.

Firman el Lcdo. Francisco Arias y Alvear (21/06/1590). ${ }^{9}$

En 30/05/1590 depone don Luis de Guzmán, residente en la Corte (45 años). Llevaba la sortija Peñafiel al dedo y se la loaron mucho mucha gente, estando en cassa del duque de Medinaceli, y un día se jugó sobre ella con el marqués de Marineo y que la dicha sortija se llevó el dicho marqués de Marineo. Firma autógrafa.

En dicho día declara don Pedro de Bobadilla, residente en la Corte (32 años, pariente de don Diego en el cuarto grado). La sortija se la vio puesta a Peñafiel y que, si hizo obligación por ella, a ella se remitía. Estando en casa del duque de Medinaceli, 10 u 11 meses atrás, se la jugó con Marineo, que se la ganó. ${ }^{10}$ Firma autógrafa.

En el día depone don Alonso de Ercilla, caballero de Santiago (52 años).

Conocía a las partes de trato y comunicación y tenía noticia de la sortija.

$\left.2^{\circ}\right)$... una señora dio la sortija sobre que es este pleito al dicho Juda Malaguín para que se la vendiesse y que este testigo oyó decir qu'el dicho Judas Malaguín la avía vendido e feriado al marqués de Peñafiel, y que no sabe si sobre la dicha venta se otorgó escritura o no, porque no se halló presente a ello, y que después este testigo le oyó desir al dicho Judas Maleguín que se avía concertado con el dicho marqués en que le bolviesse la dicha sortija y que otras joyas que le avía tomado juntamente con ella le pagaría en cierta libranza, y esto sabe, como dicho tiene, de oydas, e no sabe otra cossa ... $^{11}$

$\left.3^{\circ}\right)$ No sabía. Firma autógrafa.

En el día declara don Luis Vargas, caballero de Santiago (26 años).

Ocho meses atrás, en casa del duque de Medinaceli vio a Peñafiel con la sortija de oro y diamante, que dijo haberla comprado a Malaguí; si hizo obligación, a ella se remitía.

Ese día en esa casa Peñafiel se la jugó y se la ganó Marineo. Firma autógrafa.

\footnotetext{
${ }^{9}$ Anotación al pie: No tocan al pleyto estas preguntas ny se prueban.

${ }^{10} \mathrm{Al}$ margen: No se pudo jugar lo ageno.

${ }^{11} \mathrm{Al}$ margen: Que le bolviese la sortija a Judas Malaguí.
} 
El 4 de junio depone Gómez Carrillo, estante en la Corte (26 años).

Peñafiel había comprado al Malaguí, entre otras joyas, la sortija, librándole libranza para que la cobrase sobre las rentas de su Estado, lo que sabía por haber estado presente al otorgamiento de la entrega de las joyas; Malaguí se dio por contento con esa libranza y, sobre todo, se remitía a ésta. ${ }^{12}$

Oyó decir a los criados de Peñafiel que Marineo le había ganado la sortija en el juego. Firma autógrafa.

En el día declara Diego Becerra, residente en la Corte (35 años).

7 meses atrás un día, hablando con el Malaguí de lo que le adeudaba Peñafiel, le dijo el judío que venía de El Escorial de dar un memorial a S.M. contra el marqués de Peñafyel, porque no le pagava lo que le devía, y qu'el dicho memorial avía venydo remytido al señor presidente de Castilla, y de alli avía sido remytido a los alcaldes del crimen desta Corte, y Moreta platero le dixo al dicho Maleguín que para qué trataba de aquello, pues el marqués deseava pagalle, y este testigo le preguntó que cómo yntentaba cobrar su deuda del dicho marqués por vía criminal, siendo civil, y el dicho Malequin dixo a este testigo qu'el dicho marqués le avía llamado y a ronpido cierta libranza qu'el dicho marqués decía le a mandado para que cobrase lo que se le devía, $y$ tratando del dicho negocio este testigo oyó decir al dicho Juan Malequín qu'el dicho marqués le devía cierta cantidad de mrs. de joyas que le avía dado, a donde entraba la sortija de oro con diamante jaquelado, sobre que se litiga, y que dello y de las demás joyas le avía hecho escriptura y dádole la dicha libranza para lo cobrar en la Puebla de Cazalla, donde el dicho marqués tenía sus alimentos. ${ }^{13}$

Ocho meses atrás, vio en casa del Duque de Medinaceli jugar a los marqueses de Peñafiel y Marineo y otros caballeros y Marineo le ganó a Peñafiel cierta cantidad de dinero sobre libranzas que se davan, y en prescio de lo que le avía ganado vio este testigo cómo el dicho marqués de Peñafyel dio al de Marineo una sortija de oro esmaltada de negro con un diamante jaquelado, que es la sobre que se trata este pleito, y el dicho marqués de Marineo rescibió la dicha sortija y se llevó como cossa suya y que la avía ganado al dicho marqués de Peñafyel, y esto sabe porque, como dicho tiene, se halló presente a ello. Firma autógrafa.

Esta probanza fue presentada en Madrid, por don Diego el 7 de junio. Aun cuando las declaraciones de los testigos del actor son más expresivas y ceñidas al tema que se estaba ventilando - como no deja de reconocer en sus anotaciones marginales el relator ¿o tal vez el letrado del demandante?- que las del reo, entre ambas podemos reconstruir el tracto de los hechos: en Madrid doña María de Granada, propietaria inicial de la joya, la había puesto en manos del Malaguí para que la vendiese en su

\footnotetext{
${ }^{12} \mathrm{Al}$ margen: Que se remite a los recaudos.

${ }^{13} \mathrm{Al}$ margen: Que le ronpió el marqués la libranza.
} 
nombre; el judío la mostró al duque de Peñafiel, junto con otras valiosas preseas, que se la compró, dándole en pago una libranza contra las rentas de su Estado, concretamente, en las rentas de la Puebla de Cazalla, donde tenía asignados sus alimentos; ${ }^{14}$ luego el marqués se arrepintió y rompió la libranza, con lo que la compraventa efectuada perdió su efectividad. A partir de ahí el Malaguí se vio burlado por el noble, pues Téllez-Girón empeñó la joya en manos de don Diego Pacheco en 100 escudos, que hizo lo propio con don Alonso de Ercilla por 225 escudos.

Si es ajustado a la verdad lo dicho por los testigos del demandado, parece que la causa de que el de Peñafiel realizase esas operaciones en perjuicio del judío provienen del hecho de haber perdido, en casa del duque de Medinaceli, la sortija jugando con el marqués de Marineo,${ }^{15}$ luego de haber presumido de la joya ante los presentes en esos salones; los sucesivos empeños entiendo que vendrían motivados por el deseo de Téllez-Girón de recuperar la joya y devolvérsela al mercader tetuaní, máxime después de que éste denunciase los hechos por vía criminal ante el presidente del Consejo de Castilla.

Hay que esperar a la segunda mitad del mes de julio para que las partes vuelvan a comparecer ante el tribunal, en esta ocasión para presentar sus respectivos escritos de bien probado, a la vista de las deposiciones anteriores. El primero fue el procurador Alvear, el día 18, que se limitó a exponer que el marqués de Peñafiel había comprado la sortija junto a otras joyas y la había perdido en el juego. El día 22 el Malaguí se extendió mucho más, considerando que la sortija era suya y que estaba en posesión de don Diego, al cual se ofrecía a pagarle los 100 escudos de su empeño para que se la devolviese; si la había vendido a Peñafiel, la compraventa era nula por falta de

\footnotetext{
${ }^{14}$ Desde 1570 la Casa de Osuna anduvo en quiebra, por lo que estos alimentos serían los asignados por la justicia para el mantenimiento de su estatus nobiliario, quedando todos sus bienes en administración de los tribunales (Atienza, op. cit., pp. 328 y 339; la situación económica del marqués fue especialmente delicada en los años de este proceso, como se aprecia en la nota 294 de esa última página). Sobre los concursos nobiliarios véase mi trabajo «Procesos ejecutivos en la España castellana durante la Edad Moderna», Cuadernos de Historia del Derecho, XX, 2013, pp. 256-258.

${ }^{15}$ Se trata de don Vincenzo Beccadelli di Bologna, hijo de Gilberto, marqués de Marineo tras 1565, al que sucedió en 1577; participó en la batalla de Lepanto, acompañado de 8 caballeros principales de su Reino, así como de 16 criados con arcabuces y municiones; iba embarcado en la galera Sicilia de ese mismo Reino. Más tarde fue general en Navarino y capitán de caballos; en 1584 y 1588 fue embajador ante Felipe II, miembro de su Consejo de Guerra, pretore de Palermo (1592-1593), strategoto de Mesina en 1593-1594, 1595-1507 y 1603-1604, además de diputado del Reino cuatro veces, gobernador de la compañía de los blancos tres veces y vicario del Reino contra los bandidos en 1605. Falleció en 1615, no sin antes haberse visto envuelto en los procesos del visitador Ochoa de Luyando contra los oficiales de Sicilia, de los que salió condenado en una fuerte pena pecuniaria e inhabilitación perpetua para ocupar oficio público (Giovanna Fiume, Dizionario Biografico degli Italiani, 2008, vol. 70, voz, «Marineo, Vincenzo Beccadelli di Bologna, marchese de», disponible en la red en Treccani.it, L'Enciclopedia Italiana (http://www.treccani.it/enciclopedia/marineo-vincenzo-beccadelli-di-bologna-marchese-di_(Dizionario_Biografico)/); los datos de Lepanto en M. Fernández Navarrete, M. Salvá y P. Sainz de Baranda, Colección de Documentos Inéditos para la Historia de España, Madrid, 1843, III, p. 213.
} 
pago, prueba de ello es que el resto de las joyas se las habían reintegrado ya, pero no la sortija en cuestión, por estar en prenda; en el juego con el marqués de Marineo don Juan no había perdido la sortija, sino los 100 escudos de su empeño; todos los billetes dados por Pacheco a Ercilla demostraban que el anillo era suyo. Por todo ello volvía a reclamar la devolución del mismo. Firmada el documentado escrito el Lcdo. Diego Núñez de Morquedo. Al día siguiente el procurador Sandoval acusó la rebeldía de la parte contraria y concluyó.

La sentencia de primera instancia se demoró apenas once días, yendo firmada de los Lcdos. López de Ayala y Bonifaz; estimaron los señores del Consejo que el Malaguí había probado sobradamente su intención y que las excepciones presentadas por don Diego no tenían valor alguno, por lo que le condenaron a restituirle en el plazo de 9 días la sortija en litigio, dándole el judío los 100 ducados ofrecidos para su desempeño; en caso de no reintegrarla, debería pagarle 400 ducados; a pesar de la mala fe del noble, no condenaron en costas. El día siguiente, 4 de agosto, fue notificada a las partes: Alvear apeló y Sandoval dijo que la oía.

La apelación del reo fue formalizada en día 11; en la misma insistía que la sortija la había adquirido Peñafiel, el cual podía disponer de ella; que el marqués la había transmitido a Pacheco, por lo que el Malaguí no podía reivindicarla, ya que no le pertenecía. Firmaban el escrito el Lcdo. Arias y don Diego Pacheco. El procurador Gabriel de Sandoval, que fue notificado al día siguiente, contestó el 27 de agosto, solicitando la confirmación de la sentencia, pues estaba meridianamente claro que la sortija era de su parte: Peñafiel la entregó a don Diego y éste a Ercilla, por sucesivos préstamos, desempeñándola finalmente don Alonso cuando se le reintegraron los 225 escudos por los que la tenía en prenda. Tras las sucesivas notificaciones, Sandoval el 10 de septiembre acusó rebeldía y concluyó.

Los señores del Consejo, de nuevo, tuvieron el proceso por concluso, asignando plazo de 10 días a las partes, so pena de 10 ducados si no hiciesen probanza o se apartasen de la apelación en diez días. Esto tuvo lugar el día 15, dos días más tarde, el escribano Sarmiento notificó, a petición de Sandoval, el auto a Alvear, que contestó que se notificase a don Diego en persona, por ser auto personal, so pena de quedar sin efecto, y lo pidió por testimonio.

Sin embargo, la sentencia de recibimiento a prueba de lo nuevamente alegado, con el mencionado plazo, fue dictada por los mismos letrados el día 26. Hasta el 17 de octubre no se hizo publicación de probanzas.

Tan sólo la parte apelante presentó nuevas pruebas, a través de un nuevo interrogatorio:

$2^{\circ}$ ) si sabían que el duque de Osuna, siendo marqués de Peñafiel, compró a Malaguí la sortija y dispuso de ella como de cosa suya. ${ }^{16}$

\footnotetext{
${ }^{16} \mathrm{Al}$ margen: Esto no lo puede articular ya don Diego, que está convencido de lo contrario y ya no va por aqui el pleyto.
} 
Lo firmaban el Lcdo. Arias y el procurador Alvear. ${ }^{17}$

Probanza (Madrid, 05/10/1590):

Beltrán de Galarza, contino real, estante en la Corte (40 años).

En su presencia el duque de Osuna, siendo marqués de Peñafiel, compró la sortija, por precio que no recordaba. ${ }^{18}$

En 6 de octubre, Juan Cristóbal, vecino de Madrid (mayor de 30 años).

Depone lo mismo, añadiendo que fue medianero en la compraventa el conde de Castro, que vivía, junto a Peñafiel, en casas del marqués de Villafranca, en la calle Arenal. ${ }^{19}$

Pidió la parte de Sandoval que concluyera la contraria, que no había probado nada nuevo. Firmaba de nuevo el Lcdo. Diego Núñez de Morquedo. Evidentemente, a la altura de la probanza de la instancia de apelación la parte apelante había dejado de seguir las formalidades requeridas en el proceso; el colmo de la desfachatez fue el escrito presentado por los apelantes, sin los mínimos visos de verosimilitud.

Decía el billete en cuestión:

Digo yo, don Juan Telles Girón, marqués de Peñafiel, que por quanto Judas Malequí, judio de nación, a puesto una demanda a don Diego Pacheco ante el alcalde Otalora, en la qual le pide que mande al dicho don Diego le buelva una sortija de un diamante, la qual dice que yo se la enpeñé al dicho don Diego en cien escudos, y que era suya la dicha sortija, lo qual es relación falsa, porque yo no enpeñé al dicho don Diego la dicha sortija ni otra ninguna, y así lo declaro por ésta, firmada de mi nonbre, en Madril, a quatro de ebrero de mill y quinientos y noventa años.

El marqués de Peñafyel

La anotación marginal del relator, desde luego, no se dejó engañar por esta nueva patraña, cuando dejó constancia de que ésta no está conprobada ni se sabe cúya es y lo contrario está probado por Malagigi, sobre que cayó la sentencia del Consejo, y presentada sin tiempo.

Lo cierto es que esta cédula es el acto final del proceso; fue presentada ante el tribunal en 12 de noviembre de 1590, siendo notificada a Sandoval al día siguiente, el cual se reafirmó en la pedido y pidió se declarase la conclusión para definitiva. No deja de ser significativo que el auto en que se hacía esa declaración, firmada por los

\footnotetext{
${ }^{17}$ Se añade: Haga esta provança Juan Sarmiento, escrivano de semana. Mandose hacer esta probança a Juan Sarmiento y no la hiço él ni tubo comisión el que la hiço.

${ }^{18} \mathrm{Al}$ margen: Remítese a la escritura y no la presenta.

${ }^{19} \mathrm{Al}$ margen, dos anotaciones: Este dicho todo está borrado y no se colige d'él nada, sino está salvado lo de entre renglones; y no dice cómo lo save, sino que se lo contó Judas Malaguí.
} 
señores del Consejo, como jueces de comisión —Valle, Albornoz, don Juan de Ocón y Alderete-, llevase fecha de 14 de junio de 1597. ¡Habían pasado seis años y medio entre ambas actuaciones!

Si desde el mero punto de vista jurídico la cuestión que se dirimía en este proceso no planteaba grandes dudas, sí parece que el Consejo de Órdenes tuviera sus escrúpulos a la hora de condenar a don Diego Pacheco, miembro de la Orden y bien relacionado con la alta nobleza, frente a las demandas de un oscuro personaje, al que se le había perdido la pista en Castilla desde tiempo atrás — desde fines de agosto de 1590 no actuaba personalmente en el proceso- - O, tal vez, se presentaron otras dificultades que desconocemos. Sólo podemos hacer conjeturas al respecto.

Lo único cierto es lo que nos transmiten las últimas hojas del expediente conservado. Volvemos a encontrarnos con el Malaguí en Málaga, el primero de octubre de 1592, cuando otorgó amplios poderes para negociar en su nombre a favor del alcaide Francisco de Contreras y Figueroa, vecino de esa localidad. Le habilitó especialmente, para que en Madrid cobrase de Baltasar Suárez, vecino de dicha villa, un jarro de cristal grande con el pie y tapador de plata dorada, con su caja forrada de terciopelo verde, un escritorio de las Indias, esquinado de plata y las cenaduras de plata, una sierpe de oro con 22 esmeraldas, y 3 anillos de oro, uno con un mesi pequeño, otro con un diamante pequeño y otro con una esmeralda, que Baltasar cobró por poder suyo de Héctor Picamillo genovés, vecino de Madrid.

También le otorgó poder para fenecer pleito tratado con don Diego Pacheco por una sortija con un diamante grande chavado, que el Malaguí había comprado de doña María de Granada, vecina de Madrid, por precio de 400 ducados, pleito sentenciado por el Consejo de Órdenes; que pueda realizar todas las diligencias para cobrar la sortija.

Para que cobre del conde de Castro una pluma de oro grande con muchas esmeraldas y una grande engastonada, que el Malaguí había comprado a don Alonso de Ercilla y el conde de Castro la tiene empeñada en 100 ducados, las cuales pluma y sortija pueda recibir pagando al conde los 100 ducados. Teniendo todas esas joyas, que el apoderado las pueda vender al precio que crea conveniente.

También le da poder para convenirse con Héctor Picamillo por una cantidad de dinero por el que le tenía ejecutado al judío, como administrador que aquél era de los bienes de Antonioto Lomelín, le conceda espera o que le deje dicha cantidad en compañía para contratar en la navegación del Peñón, poniendo por caudal del dicho Héctor la persona que éste nombrare, y el dinero que debía.

Así mismo le dio poder también para tomar a cambio en cualquier cambiador $\mathrm{u}$ otra persona cantidades de cualesquier mercaderes, de Málaga, Cartagena, Toledo o Madrid, de paños, rajas, sedas, oro o plata y demás cosas por cualquier precio.

Se sometía a las justicias de Madrid, Toledo o Antequera y renunciaba al fuero de Tetuán. Asignó salario de dos ducados diarios por cada día que se ocupase en Madrid y otras partes de sus asuntos, que le pagaría sólo por su juramento. 
Fueron testigos, Antonio de Miranda, Salvador Martín y Cristóbal de Niebla, vecinos de Málaga, otorgándose ante Pedro Moreno Relosillas, escribano público.

Como puede apreciarse, el poder que acabamos de resumir, más allá del asunto que se ventilaba en el proceso por la propiedad de la sortija, indica la existencia de un diversificado entramado de relaciones personales, comerciales y territoriales ejercitadas por el 'supuesto judío de Tetuán'. En Madrid mantenía contactos con miembros de la nobleza (el conde de Castro, don Alonso de Ercilla), con factores autóctonos (Baltasar Suárez) y con mercaderes genoveses (Antonioto Lomelín, que había sido testigo suyo en nuestro proceso, Héctor Picamillo). Su ámbito geográfico, además de la capital del Reino, se extendía por la antigua capital imperial, la costa mediterránea (Málaga y Cartagena) —alcanzando la navegación del Peñón de Vélez de la Gomera, ya en manos cristianas, desde donde se producía un fuerte tráfico de cautivos con Tetuán- y una misteriosa referencia a Antequera. Evidentemente, se trataba de un amplio poder para actuar como su alter ego en Castilla durante su ausencia del Reino.

Es probable que el alcaide Contreras asumiera personalmente las negociaciones comerciales encomendadas por el Malaguí, pero lo que sabemos de cierto es que el asunto judicial pendiente lo delegó en un experto; de hecho, don Antonio se desplazó a Madrid, donde el 10 de enero siguiente sustituyó el poder en cabeza de Fernando de Ballesteros, procurador del número de la Corte. Hasta aquí la documentación cosida en el expediente; se conserva un folio aparte, con la relación escueta del proceso. En la misma se aclara que el Malaguí por aquel entonces se llamaba Domingo Picamillo y que don Diego Pacheco había fallecido; termina la reseña con una noticia ya conocida: el proceso estaba visto para sentencia en 14/06/1597, ante los cuatro señores del Consejo mencionados.

Curioso destino el de don Alonso de Ercilla, de esforzado guerrero y brillante literato convertido en intermediario comercial de mercaderes y prestamista de nobles jugadores y derrochadores; no menos lo es, desde luego, el sino de nuestro actor, el 'supuesto hebreo', transformado en mercader genovés, con un pie puesto en Tetuán y otro en la sede de la Señoría, proyectando sus negocios sobre una España en crisis. A esto se refiere David Abulafia cuando habla de un Mediterráneo en el que las identidades religiosas se distorsionaban y reconfiguraban constantemente, ${ }^{20}$ en el que los cambios de traje y de personalidad buscaban el poder actuar en distintos escenarios, transmutándose, como el Malaguí, de judío sefardí en suelo marroquí en genovés hispanizado en la Península Ibérica.

${ }^{20}$ El Gran Mar. Una historia humana del Mediterráneo, Barcelona, 2013, pp. 495 y 654. 